\title{
mssaico
}

\section{O Outro queer no contexto} conservador global

\section{Renato Contente ${ }^{1}$}

\section{Queer Otherness} in the global conservative context

\footnotetext{
1 Mestrando do Programa de Pós-Graduação em Comunicação da Universidade Federal de Pernambuco (PPGCOM/UFPE). Bolsista CNPQ. E-mail: rcontente@gmail.com
} 


\section{Resumo:}

O presente artigo se propõe a tecer considerações teóricas para se pensar a condição do Outro queer no contexto neoliberal contemporâneo. Para tal, buscarmos respostas na visão dos autores pós-estruturalistas Michel Foucault (2000), cuja ideia de épistemê é atrelada à cisão entre o Mesmo e Outro, e Judith Butler (1993; 2015), nome-chave por trás da teoria queer. Adiante, abordaremos a questão do Outro na modernidade, através de Georg Simmel (1983) e Hannah Arendt (1999). Sustentamos a condição de "estrangeiro" da população queer em um corpo social de matriz heterossexista, onde a ela é negada a condição de sujeito - situação que dispõe o Outro não necessariamente como um elemento externo ao Mesmo, mas como elemento fundamental para a própria delimitação e constituição deste Mesmo.

Palavras-chave: LGBTfobia, o Outro, Gênero, Sexualidade.

\section{Abstract:}

The present article proposes to make theoretical considerations to think the condition of the Other queer in the contemporary neoliberal context. To that end, we seek answers in the view of post-structuralists Michel Foucault (2000), whose idea of epistem is linked to the split between the Same and the Other, and Judith Butler (1993; 2015), fundamental name behind queer theory. We will also approach the question of the Other in modernity, through Georg Simmel (1983) and Hannah Arendt (1999). We maintain the "alien" condition of the queer population in a social body with a heterosexist matrix, where it is denied the condition of subject - situation that puts the Other not necessarily as an external element to the Same, but as a fundamental element for its (the Same's) delimitation and constitution.

Keywords: LGBTphobia, Otherness, Gender, Sexuality. 


\section{Introdução}

Diante de um desmanche generalizado de instituições, hábitos e afetos, dificilmente pode-se falar de uma camada da contemporaneidade que não seja atravessada pela ideia de "crise". Como aponta Chauí (2006, p. 324), vivemos em tempos inerentes à instabilidade, à dispersão, à fragmentação e ao individualismo exacerbado, em um contexto penetrado pela violência. $\mathrm{O}$ crescente espaço tomado pelo discurso conservador em escala global, aliado à engrenagem neoliberal e à fragmentação de referenciais primários, como as conexões afetivas e a relação com a tecnologia, compõe parte significativa da força motriz do estado de crise que vivenciamos atualmente.

Nesse contexto, a alteridade, possibilitada pelo espaço cedido ao Outro, encontra falhas substanciais em suas próprias condições de existência, dificultando o exercício do respeito à categoria humana em sua diversidade. Não à toa, testemunhamos, nas realidades concreta e virtual, diversas reações ao discurso conservador advindas de pontos contrahegemônicos do corpo social, ao exemplo dos levantes LGBTs, feministas, negros e indígenas. Neste artigo, nos ateremos aos indivíduos de sexualidades e gêneros que extrapolam o eixo do desejo heterossexual cisgênero (BUTLER, 2015) no contexto neoliberal, dentro do qual vivenciam as violências inerentes às pessoas que diferem dos termos estipulados pela épistemê vigente.

Foucault contextualiza a percepção do Outro ao rastrear o que considerou "as duas grandes descontinuidades da épistemê da cultura ocidental": a que inaugura a idade clássica, por volta do século XVIII, e a que, no início do século XIX, marca o limiar da modernidade ocidental (FOUCAULT, 2000, p. 18). O autor toma como exemplo o advento da loucura, construção de um discurso médico-científico no século XIX, para contextualizar a relação do Mesmo com o Outro. De acordo com o francês:

A história da loucura seria a história do Outro - daquilo que, para uma cultura é ao mesmo tempo interior e estranho, a ser portanto excluído (para conjurar-lhe o perigo interior), encerrando-o porém (para reduzir-lhe a alteridade); a história da ordem das coisas seria a história do Mesmo daquilo que, para uma cultura, é ao mesmo tempo disperso e aparentado, a ser portanto distinguido por marcas e recolhido em identidades (FOUCAULT, 2000, p. 21).

Maria Lucia Barroco (2011) propõe uma análise da sociabilidade contemporânea a partir do rastro neoliberal. A autora argumenta que as transformações operadas no capitalismo mundial, a partir da década de 1970, resultaram no agravamento da desigualdade estrutural e na degradação da vida humana e da natureza. Ao intervir na vida dos indivíduos, esse processo teria produzido uma nova dinâmica dentro do conjunto das relações sociais, especialmente por conta da insegurança vivenciada objetiva e 
subjetivamente pelos sujeitos em seu cotidiano. O pensamento dominante do capitalismo contemporâneo, portanto, justificaria as transformações operadas na vida social pela ofensiva do capital (BARROCO, 2011, p. 206).

Como situam Dardot e Laval $(2016$, p. 7), a mentalidade neoliberal é mais do que a expressão de uma ideologia ou de uma política econômica: ela compreende um sistema normativo que ampliou sua influência globalmente, tendo estendido a lógica do capital a todas as relações sociais e a todas as esferas da vida. Consiste em um "conjunto de discursos, práticas e dispositivos que determinam um novo modo de governo dos homens segundo o princípio universal da concorrência" (DARDOT; LAVAL, 2016, p. 17). Os filósofos sustentam que a crise econômica de 2008 demonstrou que o neoliberalismo engendra desastres de ordem econômica, social, ética e política na mesma medida em que se autofortalece, ao fazer surgir "um sistema de normas e instituições que comprime as sociedades como um nó de forca" (DARDOT; LAVAL, 2016, p. 8).

Barroco argumenta que o neoconservadorismo (o conservadorismo situado no contexto neoliberal atual) busca legitimação pela repressão dos trabalhadores ou pela criminalização dos movimentos sociais, da pobreza e da militarização da vida cotidiana. Para autora, essas formas de repressão implicam violência contra o Outro, sendo estas mediadas moralmente, em diferentes níveis, na medida em que objetivam a negação do Outro. Quando o Outro é discriminado, portanto, a ele é negado o direito de existir como tal ou de existir com as suas diferenças (BARROCO, 2011, p. 209).

É pertinente pontuar as subjetividades produzidas pelo neoliberalismo como mecanismos de controle e sujeição dos corpos mais elaborados do que o liberalismo clássico e o fascismo, sistemas desenvolvidos dentro de uma lógica moderna que reiterava identidades coletivas a partir de uma delimitação dualista e mais clara entre o Mesmo e o Outro. No neoliberalismo, devido à sua dinâmica específica de produção de subjetividades e à fragmentação de identidades que promove, a relação entre o Mesmo e o Outro surge mais nebulosa, movediça. A diversidade de identidades é incorporada à lógica do capital no contexto neoliberal na medida em que os indivíduos que portam essas identidades podem consumir e colaborar para a manutenção do sistema socioeconômico.

No contexto da população LGBT, isso se reflete nos processos de normatização dos corpos queer, que adquirem legitimidade ao se aproximar das ideias de masculino e feminino que amparam a heteronormatividade. Visualizamos isso no próprio processo transexualizador que "convida" as pessoas transexuais a adquirirem legitimidade social através de uma passabilidade heterossexual e cisgênera, ou a economia do desejo homossexual masculino hegemônico, que determina como desejáveis corpos brancos, não afeminados, fortes e "discretos", ao passo em que lê como abjetas representações de masculinidade que diferem dessa norma. Nesse sentido, o Mesmo e o Outro se reconfiguram e provocam tensionamentos e rupturas dentro da ideia que estipula uma unidade possível dentro das vivências abarcadas pela sigla LGBT. 
Butler (2016) nos fornece subsídios para compreender a LGBTfobia contemporânea através da biopolítica conservada pela mentalidade neoliberal. No texto em questão, a filósofa desconstrói o argumento de que as formas de violência e assujeitamento sofridas pelos integrantes dos "novos movimentos sociais", ao exemplo do próprio movimento LGBT, são "meramente culturais", e não propriamente econômicas. Se assim fosse, a autora argumenta, esses tipos de opressão seriam menos importantes do que os tipos de opressão exercidos contra classes que desempenham reconhecida centralidade na estrutura econômica da sociedade, como as mulheres, os negros e os trabalhadores. Nesse sentido, a autora não apenas defende o papel de destaque ocupado pelas questões de gênero dentro da economia política, papel este que é sobretudo de regulação sexual, mas também as violências homotransfóbicas como produto desse regime econômico.

Para Butler (2016), a construção dos sujeitos é impactada pelos múltiplos discursos e tecnologias orquestrados, em grande medida, "por duas instituições seculares e estratégicas para o funcionamento capitalista: o falocentrismo e a heterossexualidade" (2016, p. 227). Um contrassenso ao funcionamento ideal desse sistema, portanto, residiria nas sexualidades e gêneros dissidentes, não associáveis, em um primeiro momento, aos corpos dóceis, úteis e disciplinados descritos por Foucault. Butler argumenta que a regulação da sexualidade foi sistematicamente vinculada ao modo de produção adequado ao funcionamento da economia política, na medida em que o gênero normativo serve à reprodução da família normativa (BUTLER, 2016, p. 240).

A autora assinala que as operações de homotransfobia são centrais ao funcionamento da economia política, uma vez que elas constituem uma ameaça fundamental à sua própria viabilidade. Dessa maneira, o econômico, vinculado ao reprodutivo, está necessariamente atrelado à reprodução da heterossexualidade compulsória. Isso não implica que as sexualidades e gêneros dissidentes sejam deixados de fora dessa dinâmica, mas que a sua supressão é essencial para a operação daquela normatividade prévia, fortalecendo um "modo específico de produção e troca sexual que atua para manter a estabilidade do gênero, a heterossexualidade do desejo e a naturalização da família" (BUTLER, 2016, p. 242).

\section{Produção de corpos abjetos}

Lançamos mão da conceituação de corpos abjetos trazida por Butler (1993; 2015) como gatilho inicial para se pensar o Outro queer na contemporaneidade. Nesse sentido, ressaltamos a condição de "estrangeiro" da população queer em um corpo social de matriz heterossexista, onde a ela é negada a condição de sujeito - situação que dispõe o Outro não necessariamente como um elemento externo ao Mesmo, mas como elemento fundamental para a própria delimitação e constituição deste Mesmo. Assim, os sujeitos são formados através de uma matriz heterossexual excludente, onde há a produção simultânea de um 
domínio pertencente aos seres abjetos, aqueles que ainda não são 'sujeitos', mas que dão corpo justamente à exterioridade do que é tido como o domínio do sujeito "legítimo".

Os "perigos" sinalizados por esses corpos desviantes compõem o argumento de Butler $(1993 ; 2015)$ em torno dos corpos abjetos. A autora defende que as corporalidades abjetas designam as zonas "inabitáveis" da vida social, ainda que densamente povoadas por aqueles que não gozam do status de sujeito e cujas vidas "sem dignidade para existir" demarcam justamente o domínio do sujeito "legítimo". Nesse sentido, "o sujeito é constituído através da força de exclusão e abjeção, esta que produz o que é exterior ao sujeito, um exterior abjeto que está, não obstante, 'dentro' do sujeito como seu próprio repúdio fundacional" (BUTLER, 1993, p. 14).

Se a materialidade do sexo é demarcada em discurso, na visão de Butler essa própria demarcação será responsável pela produção de um domínio dos "sexos" excluídos e deslegitimados. Seguindo esse raciocínio, a autora afirma que é tão importante pensar como e com que objetivos os corpos são construídos, quanto como e com que objetivos os corpos não são construídos. Assim, é preciso se perguntar também como os corpos que "falham" ao não conseguirem se materializar como "inteiramente humanos" conseguem prover a referência exterior necessária para os corpos que, normativamente materializados, são qualificados como corpos que importam. A autora aponta que a efetivação desse "campo de deformação" estimula e legitima o questionamento sobre se os estilos de vida dos indivíduos tidos com desviantes podem ser considerados como "vida", ou mesmo se as vidas desses Outros corpos são dignas de serem protegidas, salvas e lamentadas (BUTLER, 1993, p. 27).

Tendo isso em vista, nos filiamos a Butler quanto a uma perspectiva constitutiva do Outro - ou seja, o Outro visto mais como elemento fundamental para a constituição do Mesmo do que propriamente um elemento estranho, externo ao Mesmo, um "estrangeiro". Ainda assim, consideramos pertinente trazer a perspectiva de Simmel (1983), autor de uma conceituação clássica do Outro a partir dessa segunda perspectiva. Sobretudo porque, embora localizasse o Outro como uma referência externa ao Mesmo, em leitura de Tedesco (2007, p. 64), o estrangeiro de que fala Simmel serve de referência à identidade dos grupos para definir elementos negativos do Outro.

Como descreve Tedesco (2007) ao analisar "O estrangeiro" (1983) de Simmel - texto no qual o sociólogo analisa o Outro a partir da figura do estrangeiro que começava a obter extenso relevo na Europa do início do século XX -, a condição de estrangeiro excede a do indivíduo que visita ou reside em um país que não seja o seu de origem. Ela diz respeito aos sujeitos que, em alguma medida, estão desajustados à normatividade requerida pelas estruturas de poder que circundam sua existência. Dessa maneira, o estrangeiro não possui uma dimensão de fronteira física, mas sim simbólico-social (TEDESCO, 2007, p. 64), ponto no qual reside a questão do Outro queer.

Destacadas como elementos estranhos em meio a um corpo social de condução heteronormativa, também hegemonicamente branco e cisgênero, as pessoas queer, de 
sexualidades e gêneros periféricos, como se refere Foucault (2005, p. 48), são alvo recorrente de agressões físicas e simbólicas. Estão entre os seres anormais e os corpos indóceis e indisciplinados problematizados por Foucault (2005), assim como os corpos abjetos descritos por Judith Butler (1993; 2015) e o Outro, o estrangeiro em relação a nós, de que tratam autores como Georg Simmel (1983) e Hannah Arendt (1999).

Esses sujeitos não cisgêneros e/ou não heterossexuais são violentados e assassinados com frequência alarmante no Brasil. Em 2016, foram contabilizadas 343 investidas fatais contra esses indivíduos, o maior montante desde o início das apurações anuais do Grupo Gay da Bahia, em $1970^{1}$. As estatísticas situam o país como recordista mundial de crimes contra LGBTs, com o registro de uma morte por motivações LGBTfóbicas a cada 25 horas. São indivíduos que sofrem estigmas (e não raro reproduzem-nos entre os seus pares) que repousam com indesejável estabilidade no discurso dominante.

\section{O Outro na Modernidade}

Foi em tempos sombrios, nos anos que antecederam a Primeira Guerra Mundial, que Georg Simmel (1983) avaliou a construção do imaginário em torno do estrangeiro (the stranger). O termo é tomado aqui não como a condição do indivíduo que está em outro país que não o seu originário, mas como o Outro: o corpo estranho no tecido social cuja "estranheza" é meticulosamente trabalhada no sentido de pôr em prática a lógica de exclusão articulada pelas instâncias políticas hegemônicas.

Simmel define o estrangeiro como um viajante em potencial, aquele que chega hoje, mas não necessariamente parte amanhã. É o indivíduo que consegue se introduzir em um grupo espacial simbólico, mas não é capaz de obter as condições de pertencimento efetivas compartilhadas pelos membros "autênticos" do grupo. Para o autor, "sua posição no grupo é determinada, essencialmente, pelo fato de não ter pertencido a ele desde o começo, pelo fato de ter introduzido qualidades que não se originaram nem poderiam se originar no próprio grupo" (SIMMEL, 1983, p. 182).

Tidos como "inimigos internos", os estrangeiros são parcialmente reconhecidos como integrantes do grupo sob uma condição dúbia: "se, de um lado, são imanentes e têm

\footnotetext{
${ }^{1}$ De acordo com o "Relatório 2016 - Assassinatos de LGBT no Brasil", produzido pelo Grupo Gay da Bahia, 343 lésbicas, gays, bissexuais, travestis e transexuais foram mortos em 2016. 31\% desses assassinatos foram praticados com arma de fogo, $27 \%$ com armas brancas, incluindo enforcamento, pauladas, apedrejamento, tortura e queima do corpo. O relatório aponta também que travestis geralmente são assassinadas a tiro ou espancadas na rua, enquanto gays são mortos dentro de casa, com objetos domésticos: facas, fios elétricos ou sufocados na cama. Das 343 vítimas, 173 (50\%) eram gays, 144 (42\%) travestis e transexuais, 10 (3\%) lésbicas, 4 (1\%) bissexuais e 12 (4\%) parceiros/amantes de transexuais ou travestis, além de pessoas que tinham algum envolvimento com a vítima ou que foram confundidas com LGBTs. Disponível em: <https://homofobiamata.files.wordpress.com/2017/01/relatc3b3rio-2016-ps.pdf>. Acesso em 12 de fevereiro de 2017.
} 
uma posição de membros, por outro estão fora dele e o confrontam" (SIMMEL, 1983, p. 183). Ao estrangeiro é negada a condição de "proprietário de terra", "no sentido figurado de uma substância vital que é fixa", sendo ele tácita e coercitivamente incapaz de se localizar em um "ponto ideal do ambiente social" (SIMMEL, 1983, p 184).

Em comentário sobre o texto de Simmel, Tedesco (2007) sublinha que o autor localizava o estrangeiro na dimensão da incerteza e da ambiguidade, como um indivíduo que redefinia e reorganizava não apenas os seus próprios elementos cognitivos, como também os da sociedade que o hospeda. Sendo as categorizações práticas intrínsecas aos grupos sociais, portanto, "o estrangeiro serve de referência à identidade dos grupos para definir elementos negativos do outro" (2007, p. 64).

Hannah Arendt (1999) sustenta que o ódio é cultivado e manifestado a partir de uma instância de irreflexividade. Filósofa política, alemã e judia, Arendt foi convidada em 1961 pela publicação estadunidense The New Yorker para reportar o julgamento de Adolf Eichmann, um dos funcionários do governo nazista que transportavam prisioneiros para os campos de concentração do regime. Diante de um evento amplamente midiatizado, cuja narrativa principal era orientada pela responsabilidade de Eichmann pelos assassinatos em massa, Arendt aos poucos passou a considerar o inicialmente frágil argumento de defesa do réu: não se tratava de um monstro, mas de um burocrata desconcertantemente comum.

Na perspectiva da autora, "o problema com Eichmann era exatamente que muitos eram como ele, e muitos não eram nem pervertidos, nem sádicos, mas eram e ainda são terrível e assustadoramente normais" (ARENDT, 1999, p. 166). Arendt sustenta que, do ponto de vista das instituições e padrões morais de julgamento, "essa normalidade era muito mais apavorante do que todas as atrocidades juntas", uma vez que suscitava uma nova classificação de criminoso, o hostis generis humani (inimigo da raça humana, em tradução livre), "que comete seus crimes em circunstâncias que tornam praticamente impossível para ele saber ou sentir que está agindo de modo errado" (ARENDT, 1999, p. 166).

Eichmann, por consequência, consistiria em um burocrata medíocre - um fascista em potencial, nos termos de Adorno (1950, p. 8), ou uma manifestação daquilo que Foucault define como homo oeconomicus (2008, p. 368) -, refletindo uma mentalidade geral que fora construída a partir da destituição da capacidade de pensar ${ }^{2}$ e de discernir termos morais. Uma mentalidade sistematicamente reproduzida nos termos de um estado organizado burocraticamente e fundado na biopolítica, portanto.

\footnotetext{
${ }^{2}$ Para Arendt, o ato de pensar destoa da tradição metafísica que o demarcava exclusivamente pela quietude, contemplação e passividade, em contraste com o mundo da ação. A autora enxerga o ato de pensar como a mais pura atividade humana, capaz de propiciar uma saída do mundo. Essa saída do mundo, por sua vez, diz respeito à "capacidade de romper com o cotidiano, uma descontinuidade própria da vida humana, uma parada, uma reflexão, o ato de voltar-se sobre os acontecimentos a fim de dar significado a eles". Assim, o ato de pensar significa romper com o mundo, "mas não é trocar esse mundo por um melhor, mais puro ou mais profundo, como erroneamente indicou a tradição metafísica" (ARENDT, 1995 apud ANDRADE, 2010, p. 121).
} 
Esse modus operandi, portanto, incidiria de maneira direta na capacidade reflexiva dos indivíduos. Em sua conceituação da banalidade do mal, Arendt sustenta que o mal não é radical, ou seja, "não tem raízes, não tem profundidade", consistindo, ao invés disso, em um fungo, sem raiz ou semente, que se espalha sobre uma determinada superfície: "a massa de cidadãos inaptos para a capacidade de pensar e incapazes de dar significado aos acontecimentos e aos próprios atos" (ASSY, 2001 apud ANDRADE, 2010, p. 113).

Dessa maneira, "o mal não é radical, mas pode ser extremo; ele é superficial, ainda que suas consequências sejam incalculavelmente desastrosas e monstruosas" (SOUKI, 1998; ASSIS, 2001 apud ANDRADE, 2010, p. 113). Para a Arendt, "a incapacidade de pensar oferece um ambiente privilegiado para o fracasso moral", uma vez que "o ato de pensar poderia pois não há garantias ou certezas - condicionar os seres humanos a não praticar o mal" (ANDRADE, 2010, p. 120).

Problematizando a dicotomia Mesmo/Outro, Bauman define a prática tipicamente moderna como o esforço contínuo de exterminar a ambivalência para obter condições de definir o mundo com precisão e eliminar tudo aquilo que não pudesse ser rigorosamente definido (BAUMAN, 1999, p. 15). Dessa maneira, como citado anteriormente, a intolerância se coloca como inclinação natural da prática moderna, na medida em que a construção da ordem "exige a negação dos direitos e das razões de tudo que não pode ser assimilado - a deslegitimação do outro" (BAUMAN, 1999, p. 16).

Dessa maneira, a existência é moderna na medida em que é administrada por "agentes soberanos" que defendem com sucesso o direito de gerenciar e administrar a vida coletiva: "o direito de definir a ordem e pôr de lado o caos como refugo que escapa à definição" (BAUMAN, 1999, p. 15). Nesse sentido, aquilo que escapa à definição assistida pelo poder é considerado subversivo, afinal, o Outro dessa soberania são as áreas proibidas, de agitação e desobediência, de colapso da lei e da ordem (BAUMAN, 1999, p. 16). Como o autor sustenta:

Em dicotomias cruciais para a prática e a visão da ordem social, o poder diferenciador esconde-se em geral por trás de um dos membros da oposição. O segundo membro não passa do outro do primeiro, o lado oposto (degradado, suprimido, exilado) do primeiro e sua criação. Assim, a anormalidade é o outro da norma, o desvio é o outro do cumprimento da lei, a doença é o outro da saúde, a barbárie o outro da civilização, o animal o outro do humano, a mulher o outro do homem, o forasteiro o outro do nativo, o inimigo o outro do amigo, "eles" o outro de "nós", a insanidade o outro da razão, o estrangeiro o outro do súdito do Estado, o público leigo o outro do especialista. Um lado depende do outro, mas a dependência não é simétrica. O segundo lado depende do primeiro para o seu planejado e forçado isolamento. O primeiro depende do segundo para sua autoafirmação (BAUMAN, 1999, p. 23). 
Para o autor, a natureza dicotômica da modernidade produz seus próprios refugos ao mesmo tempo em que se esforça para elimininá-los, dado que eles "desafiam a classificação e a arrumação da grade" e são a "mistura desautorizada de categorias que não devem se misturar" (BAUMAN, 1999, p. 23). Tendo em vista que o Estado moderno tinha como fim a constituição de uma sociedade racionalmente planejada, "ordeira e afinada com os preceitos da razão", Bauman lança mão de uma metáfora na qual atribui ao Estado o papel de "jardineiro".

De acordo com ele, a mentalidade moderna "desmantelou os mecanismos existentes de reprodução e auto-equilíbrio da população", colocando em seu lugar "mecanismos construídos com a finalidade de apontar a mudança na direção do projeto racional" (BAUMAN, 1999, p. 29). Na visão do autor, este projeto estabelecia como critério de atuação a divisão da população em duas categorias, que remetem, por sua vez, à biopolítica tratada por Foucault (2005): "plantas úteis", a serem estimuladas e cuidadosamente cultivadas, e "ervas daninhas", a serem removidas ou arrancadas.

\section{A ameaça do Outro queer}

O Outro consiste em uma categoria que denota a capacidade das sociedades de criarem um senso de pertencimento, identidade e status social que define a construção das identidades das maiorias e minorias (ZEVALLOS, 2011). Trata-se de uma potente categoria simbólica vastamente instrumentalizada politicamente, que compreende indivíduos, grupos ou nações estrategicamente dispostos à margem dos poderes hegemônicos, sejam estes de ordem econômica, social, racial ou sexual.

O termo "Outro" possui limitações epistemológicas que merecem ser levadas em consideração. O Outro consiste em uma instância simbólica produzida de um ponto de vista dominante dentro de uma lógica de oposição binária. Quando nos referimos a este termo, estamos conscientes dessa contradição e reiteramos seu caráter passível de crítica, não sendo, portanto, nosso objetivo fortalecer seu uso por um viés etnocêntrico ${ }^{3}$, que consistiria em "privilegiar um universo de representações propondo-o como modelo e reduzindo à insignificância os demais universos e culturas 'diferentes'” (CARVALHO, 1997, p. 181).

Aqui nos atemos ao Outro como forma de evidenciar uma construção simbólica que é utilizada para estigmatizar grupos e efetivar uma legitimação social do ódio. Sublinhamos, portanto, um tipo de violência que não só foi concretizada historicamente "por meio da violência física contida nas diversas formas de colonialismos, mas, sobretudo,

\footnotetext{
3 De acordo com Dibyendu, o estudo de uma "outra cultura" é uma área cuja origem remonta aos pesquisadores orientalistas, que entendiam as populações do Terceiro Mundo como fracas e de moralidade duvidosa. Em uma perspectiva eurocêntrica, essas "outras" populações precisariam passar por um processo civilizatório para se adequar à cultura e aos valores legítimos europeus (2013, p. 26).
} 
disfarçadamente por meio daquilo que Bourdieu chama violência simbólica" (CARVALHO, 1997, p. 181).

Butler propõe em "Problemas de gênero" (2015) justamente um questionamento da dicotomia Mesmo/Outro historicamente atribuída ao modelo de gênero conservador, em que o Mesmo consiste na figura masculina, e o Outro em seu oposto feminino. Para a autora, o poder é mais do que a permuta entre sujeitos ou uma relação de inversão constante entre um sujeito e um Outro: ele produz a estrutura binária em que se pensa o conceito de gênero, sendo preciso desmascarar o regime epistemológico da presunção da heterossexualidade "como produtor e reificador dessas categorias ostensivamente ontológicas". (BUTLER, 2015, p. 8). Nesse sentido:

A noção de que pode haver uma "verdade" do sexo, como Foucault a denomina ironicamente, é produzida precisamente pelas práticas reguladoras que geram identidades coerentes por via de uma matriz de normas de gênero coerentes. A heterossexualização do desejo requer e institui a produção de oposições discriminadas e assimétricas entre "feminino" e "masculino", em que estes são compreendidos como atributos expressivos de "macho" e de "fêmea". A matriz cultural por meio da qual a identidade de gênero se torna inteligível exige que certos tipos de "identidade" não possam "existir" (BUTLER, 2015, p. 44).

Butler destaca que as identidades "que não podem existir" são historicamente tidas como falhas de desenvolvimento ou impossibilidades lógicas por não se conformarem às normas da inteligibilidade cultural hetenormativa. No entanto, sua proliferação possibilita expor os limites e os objetivos reguladores dos mecanismos de inteligibilidade no sentido de "disseminar, nos próprios termos dessa matriz de inteligibilidade, matrizes rivais e subversivas de desordem de gênero" (BUTLER, 2016, p. 44).

Para driblar as limitações impostas pelo modelo binário Mesmo/Outro na problemática LGBT, Ganguli Dibyendu (2013, p. 26) nos orienta a pensar a questão do Outro a partir da teoria queer de Butler (2015), para quem as identidades não são fixas e nem determinam quem somos. Como recupera o autor, as identidades queer são caracterizadas por resistirem à perspectiva heterossexual convencional, desfazendo a dicotomia "heterossexual-homossexual" ao situar-se fora dessa estrutura. Dessa maneira, os estudos queer sustentam que essa dicotomia não é uma necessidade biológica ou cultural, mas antes o produto de uma ideologia hegemônica que restringe e compele os desejos dos indivíduos (DIBYENDU, 2013, p. 26)

Como alerta Dibyendu (2013, p. 25), um reconhecimento simplista da diversidade humana convencional, combinada a uma perspectiva etnocêntrica, pode nos conduzir a um pensamento hierárquico ou estereotipado acerca do "diferente", nos direcionando ao erro de enxergar de maneira homogênea uma categoria humana tão complexa como a população 
LGBT. Apesar desse aspecto limitante, utilizaremos como ferramenta analítica o esquema binário Mesmo/Outro (self/Other). O Outro, portanto, constitui uma das faces de uma dicotomia que opõe duas categorias de indivíduos (DIBYENDU, 2013, p. 25), ou como define Foucault (2000, p. 8), os indivíduos em consonância com uma épistemê e os indivíduos que dela destoam em alguma medida.

Dibyendu sublinha que, em uma sociedade heterossexista, a homossexualidade (e podemos considerar outras sexualidades consideradas periféricas) é o Outro da heterossexualidade. Para o autor, as diferenças sexuais são o resultado da exclusão e internalização da questão sexual do Outro (sexual 'Otherness'). Consideraremos, portanto, os comentadores de mensagens LGBTfóbicas nas redes sociais como sendo os indivíduos Mesmos heterossexistas, que através da adesão ao discurso hegemônico desqualificam a existência dos indivíduos Outros, aqueles que não se conformam a uma matriz heterossexual de conceituação do gênero e do desejo (BUTLER, 2015, p. 8).

Como consequência disso, as pessoas de sexualidades e gêneros dissidentes enfrentam diferentes formas de perseguição por parte de diversos agentes da sociedade. $\mathrm{Na}$ perspectiva de Dibyendu, a exclusão social e a desigualdade estão intimamente relacionadas ao conceito do Outro, sendo substrato da dinâmica das relações de poder. Nesse sentido, o autor sustenta que o grupo interno (Mesmo) consolida e define sua identidade como superior em relação aos outros grupos (Outro), uma vez que as estruturas de poder perpetuam a desigualdade e atuam no sentido de minar continuamente as tentativas de empoderamento dos grupos menos favorecidos (DIBYENDU, 2013, p. 25).

Em linha de pensamento semelhante, Butler (1993) defende que as normas regulatórias do sexo atuam de maneira performativa para "constituir a materialização dos corpos e, mais especificamente, materializar o sexo do corpo, materializar a diferença sexual a serviço da consolidação do imperativo heterossexual" (BUTLER, 1993, p. 13), o Mesmo que atua sobre os mecanismos reguladores da épistemê ocidental.

\section{Considerações finais}

O artigo procurou mostrar como o Outro queer se situa no contexto neoliberal contemporâneo, a partir das fronteiras simbólico-sociais que delimitam sua existência enquanto "estrangeiro" dentro de um tecido social heterossexista. É nesse espaço fronteiriço onde é radicalizada a cisão entre o Mesmo e o Outro e suas reconfigurações no contexto neoliberal, e também onde os indivíduos LGBTs vivenciam a substituição, alteração e redefinição de "solidariedades, integrações, raízes, direitos e vínculos comunitários", elementos de que tratou Simmel (1983) em "O estrangeiro". Nessas condições, o Outro queer ocupa um lugar permanente de lutas e resistências, de ordem política e discursiva, mas também social e econômica, dado que as operações de LGBTfobia são centrais ao funcionamento da econômica política, como sustenta Butler (2016). 
Uma vez que a mentalidade neoliberal produz novos tipos de subjetivação, a partir de um quadro geral em que impera a precariedade da vida humana (DARDOT; LAVAL, 2016, p. 9), a ação coletiva é dificultada em nome de um estado de competição interindividual que transpõe a centralidade econômica para todos os âmbitos da vida (FOUCAULT, 2008; DANNER, 2011). Como sustenta Barroco (2011, p. 209), as formas de repressão que emergem nesse contexto produzem diversos tipos de violência contra o Outro, objetivando sua negação. Quando o Outro é discriminado, portanto, a ele é negado o direito de existir como tal ou de existir com as suas diferenças.

Em sentido semelhante, Butler (1993) argumenta que aos indivíduos cujos corpos são tidos como abjetos é negada a própria condição de sujeito: são vidas sem dignidade para existir, deslegitimadas em sua própria natureza, existentes em constante condição de negação de si mesmas. Nesse sentido, o Mesmo do Outro abjeto consistiria nos corpos saudáveis, normativos e economicamente produtivos. Corpos que são acolhidos pelo capitalismo e aptos a atuar com o fim de seu pleno funcionamento, seja através de postos de trabalho precários, seja através da função normativa de manutenção da família heterossexual, cisgênera e monogâmica.

Assim, podemos remeter a Foucault, para quem épistemê atual exige corpos dóceis, úteis e disciplinados, produzidos a partir da criação de "identidades fixas, dos papéis sociais e sexuais bem definidos, da heteronormatividade, dos determinantes binários dos sexos e dos gêneros e dos discursos ascéticos" (PERES, 2011, p. 72). Se o indivíduo "ideal" (Mesmo), portanto, deve portar um corpo no qual materializa os discursos reguladores e disciplinares advindos das ações do biopoder, inscrições nos corpos que sinalizam desvios a essa lógica opressora cartesiana implicam contra-poderes, resistência e enfrentamento. Nesse contexto, o Outro queer, esteja ele contemplado pela limitante sigla LGBT ou a extrapole, tem papel fundamental na linha de frente que pode subverter as narrativas hegemônicas que suprimem sua própria existência.

Artigo recebido em 21 jul. 2017. Aprovado para publicação em 30 set. 2017.

\section{Referências}

ANDRADE, Marcelo. "A banalidade do mal e as possibilidades da educação moral: contribuições arendtianas". Revista Brasileira de Educação, Vol. 15(43), 2010, p. 110-125. Disponível em: <http://dx.doi.org/10.1590/S1413-24782010000100008>. Acesso em: 21/06/2017.

ARENDT, Hannah. Eichmann em Jerusalém. São Paulo: Companhia das Letras, 1999. Livro digital. 
BARROCO, Maria Lucia. "Barbárie e neoconservadorismo: os desafios do projeto éticopolítico". Serviço Social e Sociedade, n. 106, São Paulo, p. 205-2018. Disponível em: < http://dx.doi.org/10.1590/S0101-66282011000200002 >. Acesso em 19/06/2017.

BAUMAN, Zygmunt. Modernidade e ambivalência. Rio de Janeiro: Zahar, 1999.

BUTLER, Judith. Bodies that matter. Nova Iorque: Routledge New York \& London, 1993. “Meramente cultural”. Ideia, Vol. 7(2), São Paulo, p. 227-248. Problemas de gênero. Rio de Janeiro: Civilização Brasileira, 2003.

CARVALHO, José Carlos de Paula. "Etnocentrismo: inconsciente, imaginário e preconceito no universo das organizações criativas”. Interface, Vol. 1(1), 1997, São Paulo, p. 181-186. Disponível em: <http://dx.doi.org/10.1590/S1414-32831997000200014>. Acesso em 11/06/2017.

CHAUÍ, Marilena. Cultura e democracia - O discurso competente e outras falas. São Paulo: Cortez, 2006.

DANNER, Fernando. Biopolítica e liberalismo: a crítica da racionalidade política em Michel Foucault. 2011. 168 f. Tese (Doutorado em Filosofia) - Pontifícia Universidade Católica do Rio Grande do Sul, Porto Alegre, 2011. Disponível em: <http://repositorio.pucrs.br/dspace/handle/10923/3504>. Acesso em 23/06/2017.

DARDOT, Pierre; LAVAL, Christian. A nova razão do mundo: ensaio sobre a sociedade neoliberal. São Paulo: Boitempo, 2016.

DIBYENDY, Ganguli. “Negotiating Sexual 'Otherness’: An Exploratory Study of Harassment on Male Homosexuals in Metropolitan Kolkata, India”. International Research Journal of Social Sciences, Vol. 2(3), Índia, 2013, p. 25-30. Disponível em: $<$ http://www.isca.in/IJSS/Archive/v2/i3/5.ISCA-IRJSS-2013-028.pdf>. $\quad$ Acesso em: 23/06/2017.

FOUCAULT, Michel. As palavras e as coisas. São Paulo: Martins Fontes, 2000. . A ordem do discurso. São Paulo: Loyola, 2014. . História da Sexualidade I - A vontade de saber. Rio de Janeiro: Graal, 2005. Nascimento da Biopolítica. São Paulo: Martins Fontes, 2008.

LIMA, Fátima. Corpos, gêneros, sexualidade: políticas de subjetivação. Porto Alegre: Rede Unida, 2014. Disponível em: <http://www.redeunida.org.br/editora/biblioteca-digital>. Acesso em 19/07/2017. 
MISKOLCI, Richard; PELÚCIO, Larissa. Discursos fora da ordem: sexualidades, saberes e direitos. São Paulo: Annablume, 2012.

PERES, William Siqueira. Travestis: corpos nômades, sexualidades múltiplas e direitos políticos. In: SOUZA, Luís Antonio Francisco (Org.). Michel Foucault: sexualidade, corpo e direito. Marília: Oficina Acadêmica; São Paulo: Cultura Acadêmica, 2011. Disponível em: $<$ https://www.marilia.unesp.br/Home/Publicacoes/foucault_book.pdf $>$. Acesso em: 10/06/2017.

SIMMEL, Georg. O estrangeiro. In: FILHO, Evaristo de Moraes (Org.). Georg Simmel: sociologia. São Paulo: Ática, 1983.

TEDESCO, João Carlos. “Georg Simmel e as ambiguidades da modernidade”. Ciências Sociais Unisinos, Vol. 43, São Leopoldo (RS), 2007, 57-67. Disponível em: $<$ http://revistas.unisinos.br/index.php/ciencias_sociais/article/view/5648>. Acesso em 20/06/2017.

THIOLLENT, Michel. "Maio de 1968 em Paris: testemunho de um estudante”. Tempo Social, 10(2), São Paulo, p. 63-100. Disponível em $<$ http://dx.doi.org/10.1590/ts.v10i2.86781> . Acesso em 14/07/2017.

ZEVALLOS, Zuleyka. “What's Otherness?”. Other Sociologist, 2011. Disponível em: $<$ https://othersociologist.com/sociology-of-gender/>. Acesso em 2 